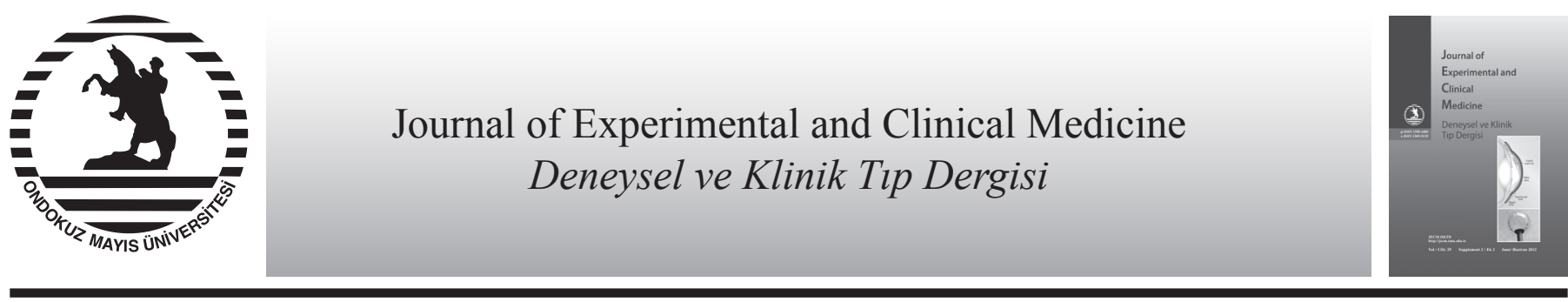

Klinik Araştırma / Clinical Research

doi: $10.5835 /$ jecm.omu.29.s2.009

\title{
Travmatik katarakt olgularında görsel sonuçlarımız ve cerrahinin zamanlaması
}

Visual outcomes and timing of surgery on traumatic cataract cases

Volkan Yeter, İnci Güngör*

Ondokuz Mayıs Üniversitesi, Tıp Fakültesi, Göz Hastalıkları Anabilim Dalı, Samsun, Türkiye

\begin{tabular}{|c|c|}
\hline \multicolumn{2}{|c|}{ MAKALE BİLGÍLERİ } \\
\hline \multicolumn{2}{|c|}{ Makale geçmişi } \\
\hline Geliş & $30 / 06$ / 2011 \\
\hline Kabul & 25 / 07 / 2011 \\
\hline
\end{tabular}

* Yazışma Adresi:

İnci Güngör

Ondokuz Mayıs Üniversitesi Tıp Fakültesi

Göz Hastalıkları Anabilim Dalı, Samsun,

Türkiye

E-posta: inci.gungor@omu.edu.tr

Anahtar Kelimeler:

Travmatik katarakt

Görsel prognoz

İntraoküler lens

Cerrahi

Keywords:

Traumatic cataract

Visual prognosis

Intraoculary lens

Surgery

\section{ÖZET}

Çalışmamızın amacı travmatik kataraktlı olgularımızda cerrahi sonrası görsel prognozun belirlenmesi ve görme düzeyine etki eden faktörlerin incelenmesi amaçlanmıştır. Aralık 2007 ve Aralık 2010 tarihleri arasında travmatik katarakt nedeniyle cerrahi uygulanan hastalar retrospektif olarak incelendi. Tüm hastalar için yaş, cinsiyet, yaralanma tipi, yaralanma ile katarakt cerrahisi arasındaki süre, cerrahi teknik, ön ve arka kapsülün durumu, vitre kaybı olup olmadığı, yerleştirilen intra oküler lens tipi ve yeri, cerrahi sonrası takip süresi ve en iyi düzeltilmiş görme keskinliği kaydedildi. Olguların bu parametreler açısından klinik özellikleri değerlendirildi. Çalışmaya yaşları 4 ile 77 arasında değişen 16 hastanın (14'ü erkek, 2'si kadın) 16 gözü dahil edildi. Hastaların 2'sinde kapalı kornea perforasyonu, 11'inde sadece kornea perforasyonu ve 3'ünde kornea-skleral perforasyon mevcuttu. Primer onarımdan ortalama 21,9 (1-120) gün sonra katarakt cerrahisi yapıldı. Hastaların 2'sine intraoküler lens konulmazken, diğer hastalarda kapsül içi veya sulkusa lens konuldu. Hastaların cerrahi sonrası ortalama takip süresi 6,5 (1-17) ay olup, son kontrollerindeki en iyi düzeltilmiş görme keskinliği ortalama 0,49 Snellen sırası idi. Travmatik katarakt cerrahisi için ideal bir cerrahi teknik ve zamanlama bulunmamaktadır. Her olgu kendi içinde değerlendirilip en uygun cerrahi planlama yapılmalıdır. Bu bilgiler ışığında, çalışmamızdaki olgularımızın büyük çoğunluğunda, sonuç görme keskinliği açısından tatmin edici sonuçlar elde edilmiştir.

J. Exp. Clin. Med., 2012; 29:S93-S96

\section{ABSTRACT}

The aim of this study was to identify the visual prognosis postoperatively and to evaluate the factors those affect the visual acuity among cases of traumatic cataracts. The data from cases who underwent surgical intervention due to traumatic cataract between December 2007 and December 2010 were collected retrospectively from the hospital records. Age, gender, the type of damage, the time of surgery, the method for the surgery, intraocular lens type and localization, follow up period and the best corrected visual acuity were recorded for each case. The clinical characteristics of the cases were evaluated in the aspects of these parameters. Sixteen eyes of 16 cases within an age range between 4 and 77 years were included to the study. Two cases had intact corneal perforation (no leakage), 11 cases had only corneal perforation and 3 cases had cornea-scleral perforation. The mean interval between the primary repair and the cataract surgery were 21.9 (1-120) days. No lenses implanted to two cases, and sulcus or in the bag lenses were implanted to the others. Mean follow up period was 6.5 (1-17) months and mean best corrected visual acuity was 0,49 Snellen chart lines at the last examination. There is no ideal technique and time for traumatic cataract surgery. The most suitable time and strategy for the surgery should be determined on the individual base. However, satisfactory visual results were reached in most of our cases.

J. Exp. Clin. Med., 2012; 29:S93-S96

(C) 2012 OMU

\section{Giriş}

Travma, gelişmekte olan ülkelerde tek taraflı körlüklerin önemli nedenlerinden biridir (Khatry ve ark., 2004). Oküler travma vakalarının \%27-\%65'inde travmatik katarakt oldu- ğu bildirilmiştir (Dannenberg ve ark ., 1992; Slusher ve ark., 1992; Pieramici ve ark., 1997). Amerikan Oküler Travma Derneği'nin bir uzantısı olan ve 17.000 vaka ile dünyanın en geniş göz hasar kayıtlarına sahip olan Birleşik Devletler Göz 
Yaralanmaları Forumu (USEIR)'nun verilerine göre ciddi göz yaralanmalarının hemen daima yarısında lens hasarı bulunmaktadır (May ve ark., 2000). Travmatik katarakta neden olan yaralanmaların sırayla oyun oynarken, ev işleri esnasında veya çalışırken meydana geldiği ve en sık tahta çubuk, taş ve metal tel ile gerçekleştiği tespit edilmiş̧ir (Mehul ve ark., 2011).

Travmatik katarakt için cerrahi sonrası görsel kazanım karmaşık bir sorundur. Çünkü postoperatif nihai görme, travma sonrası hasarlanmış olma ihtimali yüksek olan retinal veya korneal yapıların fonksiyonel bütünlüğ̈̈ne fazlasıyla bağl1dır. USEIR verilerine göre, travmatik kataraktı olan olguların $\% 48$ 'inde arka segment hasarı bulunmaktadır (Ferenc, 2010). $\mathrm{Bu}$ durum, travmatik katarakta olan yaklaşımı, temelde tanı tekniğinin ve tedavinin aynı olduğu senil katarakta olan yaklaşımdan farklı kılmaktadır.

Katarakt desantralize ve küçük bir lezyon olarak ortaya çıktıysa ve ilerleme eğilimi yoksa cerrahi gerekmeyebilir. Fakat travmatik olguların çoğunda olduğu gibi, kataraktın yoğun olduğu ve kapsül bütünlüğünün bozulduğu durumlarda katarakt cerrahisi gereklidir. Katarakt cerrahisi, kapalı glob yaralanmalarından hemen sonra ve açı glob yaralanmalarinda primer onarım esnasinda yapılırsa primer, daha sonraki bir zaman diliminde yapılırsa sekonder yaklaşım olarak isimlendirilmektedir (Rumelt ve Rhany, 2010). Primer cerrahi, lensin şişmesine bağlı göz tansiyonu yükselmesinin ve antijenik lens proteinlerinin salınımına bağlı enflamasyonun önlenmesi, postoperatif dönem için retinal yapıların direk görüntülenmesinin sağlanması gibi avantajlar sağlar. Ambliyopi gelişebilecek yaş grubundaki hastalarda, primer cerrahi ve intraoküler lens (IOL) implantasyonu ile erken rehabilitasyon sağlanmaktadır. Travmatik gözlerde proliferatif vitreoretinopati (PVR) oluşumunun en önemli nedenlerinden biri vitreus ile lensin temasa geçmesi sonucu oluşan proliferasyondur (Cardillo ve ark., 1997). Primer cerrahi, bu komplikasyonun ortaya çıkma olasılığını azaltırken hastayı ilerleyen süreçte ek cerrahi girişim veya girişimlerin ekonomik maliyet ve psikolojik etkilerinden de uzaklaştırmaktadır. Sekonder cerrahide ise göz gerekli tedavilerle daha sakin bir duruma getirilmiş ve en uygun cerrahi prosedür planlaması açısından yeterli zaman kazanılmıştır. Bu süreçte korneal sütürler alınabilir, korneanın yeni refraktif durumuna en uygun torik İOL seçimi mümkün olabilir.

Çalışmamızda, travmatik katarakt cerrahisi uyguladığımız hastaların görsel prognozlarının belirlenmesi ve zamanlama başta olmak üzere nihai görme düzeyine etki eden faktörlerin incelenmesi amaçlanmıştır.

\section{Metod}

Çalışmamızda, Aralık 2007 ve Aralık 2010 tarihleri arasında kliniğimize travmatik glob yaralanması nedeniyle acil olarak başvuran ve travmatik katarakt nedeniyle cerrahi girişim uygulanan 16 hastanın 16 gözü retrospektif olarak incelendi. Tüm travma hastalarımıza sistemik ve topikal olarak profilaktik endoftalmi tedavisi uygulandi. Hastalar taburcu edildikten sonra da rutin takiplere çağrıldı. Takiplerde, Snellen Eşeli ile görme keskinliği ölçüldü. Intraoküler basınç ölçümü, biyomikroskop ile ön segment muayenesi ve fundus muayenesi yapıldı. Ambliyopi açısından riskli yaş grubundaki hastalara en erken sürede görme rehabilitasyonu sağlandıktan sonra bu hastalar ambliyopi açısından takip ve tedaviye alındı. Tüm hastaların cerrahisi aynı cerrah tarafindan uygulandı. Tüm hastalar için yaş, cinsiyet, yaralanma tipi, yaralanma ile katarakt cerrahisi arasındaki süre, cerrahi teknik, ön ve arka kapsülün durumu, vitre kaybı olup olmadığı, yerleştirilen İOL tipi ve yeri, cerrahi sonrası takip süresi ve en iyi düzeltilmiş görme keskinliği (EIDGK) kaydedildi.

\section{Bulgular}

Travmatik katarakt nedeniyle cerrahi girişim yapılan 14'ü erkek 2'si kadın 16 hastanın yaş ortalaması 29.4 (4-77) yıl idi. Travmatik gözlerin hepsi tek taraflı olup, 11'i sağ, 5'i

Tablo 1. Çalışmamızdaki olguların genel özellikleri gösterilmektedir.

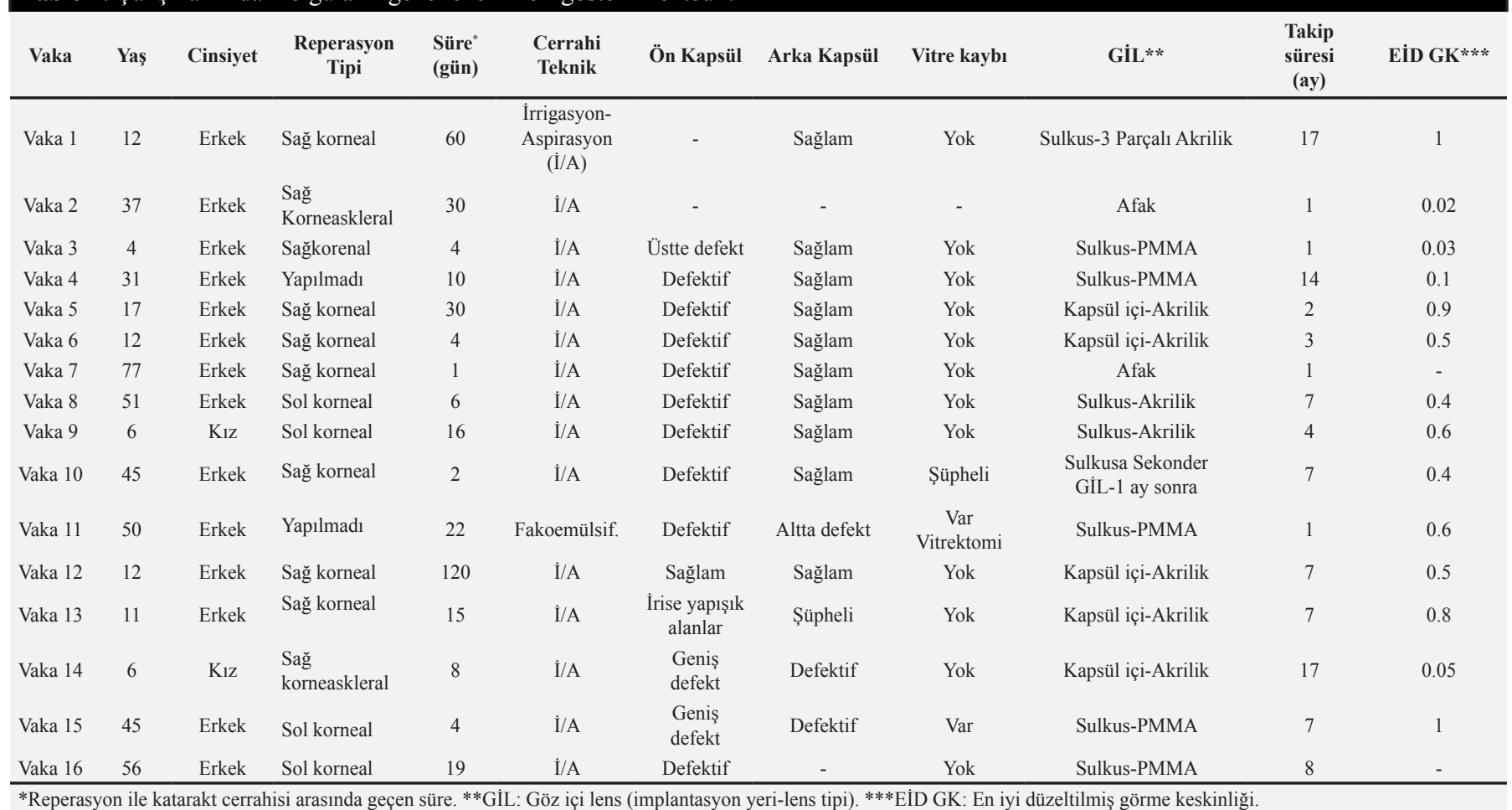


sol gözdü. Hastaların 2'sinde (\%12,5) kapalı kornea perforasyonu bulunmaktaydı. Bu hastalara primer onarım yapılmadan medikal takip ve tedavi uygulandı. Diğer 14 hastanın üçüne korneaskleral perforasyon $(\% 18,8), 11$ 'ine de sadece korneal perforasyon $(\% 68,8)$ nedeniyle başvurdukları gün içinde glob bütünlüğünü sağlamaya yönelik primer cerrahi onarım yapıl-

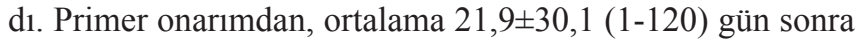
katarakt ekstraksiyonu ve İOL implantasyonu yapıldı. İki hasta afak bırakılırken, 5 hastada İOL kapsül içine $(\% 43,8)$ ve 9 hastada sulkusa $(\% 43,8)$ implante edildi. Kullanılan İOL'ler 3 parçalı akrilik veya tek parça polymetilmetakrilat (PMMA) idi. İOL gücü hesaplaması, diğer göze göre yapıldı. Cerrahi metod olarak bir hastada fakoemülsifikasyon, diğer tüm hastalarda küçük kesiden irrigasyon-aspirasyon ile ekstrakapsüler katarakt ekstraksiyonu (EKKE) uyguland1. Dokuz hastada $(\% 56,3)$ katarakt cerrahisi öncesi ön kapsülün perfore olduğu, 2 hastada $(\% 12,5)$ şüpheli ve diğer 5 hastada $(\% 31,3)$ da sağlam olduğu tespit edildi. Arka kapsülün cerrahi öncesi 3 hastada $(\% 18,8)$ bütünlüğünün bozulduğu, 3 hastada $(\% 18,8)$ bütünlüğünün şüpheli olduğu ve diğer 10 hastada $(\% 62,5)$ ise sağlam olduğu belirlendi. Erken postoperatif komplikasyon olarak 5 hastada $(\% 31,3)$ ön kamarada yoğun membran gelişti ve erken dönemde başka bir komplikasyon ile karşılaŞ1lmad1. Hastaların cerrahi sonrası ortalama takip süresi 6,5 (1-17) ay idi. Son kontrollerindeki EIDGK 0,5 $\pm 0,4$ Snellen sırası idi. Çalışmamızdaki olguların genel özellikleri Tablo 1 'de gösterilmektedir.

Son kontroldeki sferik refraksiyon kusuru ortalamas1 $-1,4 \pm 1,7$ (-5 ile 0,5$)$ dioptri iken, ortalama astigmatizma $-3,7 \pm 1,9$ (-6,5 ile 0) dioptri idi. Hastaların 6'sına katarakt cerrahisi sonrası ilk bir yıl içinde yitrium-aluminium-garnet (YAG) lazer ile arka kapsülotomi yapıldı. Son kontroldeki göz içi basınç değerlerinin ortalaması 11,3 $\pm 3,9 \mathrm{mmHg}$ iken, hiçbir hastada sekonder glokom gelişmedi. Postoperatif komplikasyon (yoğun ön kamara reaksiyonu) gelişen 5 hastanın 4'ünün son kontrollerindeki EIDGK düzeyi 0,5 altında bulunmaktayd1.

\section{Tartışma}

Travmatik kataraktlı olgularda cerrahi ile görsel kazanımın sağlanması komplike bir durumdur. Travmaya bağlı olarak eşzamanlı ortaya çıkabilen, retinal ve korneal sorunlar cerrahi sonrası görsel prognozu negatif yönde etkileyen önemli etkenlerdir (Rumelt ve Rehany, 2010 ).

Çalışmamızdaki olguların büyük çoğunluğu, korneal perforasyona bağlı ortaya çıkan travmatik katarakt olguları olduğu için, çalışmamızda görsel prognozu en çok etkileyen faktörler korneaya ait faktörlerdir. Bu durum, çalışmamızdaki olguların yüksek korneal astigmat düzeylerine sahip olmalarını da açıklamaktadır. Hiçbir hastamızda takipte oldukları zaman dilimi içerisinde retinal komplikasyon gelişmemiştir. Literatürde travmatik olgulara lens implantasyonu oranı \%78 ile \%81 arasındadır (Synder ve ark., 1999; Mehul ve ark., 2011). Çalışmamızda bu oran \%87,5'dir. Brar ve arkadaşları, (2001) daha iyi görme keskinliği için ana etkenin postoperatif komplikasyonlar olduğunu ve kapalı glob yaralanmalı hastalarda \%38,8, açık glob yaralanmalı hastalarda da \%86,4 oranında etkili olduğunu tespit etmişlerdir. Çalışmamızda ise postoperatif komplikasyon olarak erken dönemde yoğun ön kamara reaksiyonu ve membran oluşumu görülen 5 hastada $(\% 31,3)$, diğerlerine nazaran EIDGK'leri düşük bulunmuştur.
Brar ve arkadaşlarının (2001) ve bizim çalışmamızda ortaya çıkan başarı oranlarındaki bu farklılık, oküler travma tipinin farklı olmasına, başka oküler doku yaralanması varlığına veya cerrahi uygulamadaki farklılıklara bağlanabilir. Aldakaf ve arkadaşlarının (2006) çalışmasında, sonuç görme keskinliğini belirleyen ana iki etkenin, başlangıç görme keskinliği ve hasar oluşma mekanizması olduğu belirtilmektedir. Başka bir çalışmada Wos ve arkadaşları (2006), perforan ve perforan olmayan gözlerde gelişen kataraktların görsel sonuçları arasında anlamlı fark tespit etmemişlerdir. Hastanın yaşının görme prognozunu etkileyen en önemli faktör olduğunu bildiren çalışmalar da bulunmaktadır (Sternberg ve ark., 1984; Mehul ve ark., 2011). Rumelt ve arkadaşlarının (2010) çalışmalarında, görsel prognozu etkileyen ana etkenin santral kornea perforasyonu ve retina dekolmanı olduğu istatistiksel olarak belirlenmiştir. Çalışmamızda, perforasyon tipi ve hastanın yaşı ile görme düzeyi arasında istatistiksel olarak anlamlı bir ilişki saptanmadı. Bu olgu sayımızın az olması ile ilişskilendirilebilir.

Gradin ve Yorston (2001), 215 hasta ile yaptıkları bir çalışmada, postoperatif 4. haftada görme keskinliği 20/60 ve üzerinde olanların oranı \%64,7 olarak tespit edilmişti (Gradin ve ark., 2001). Görme düzeyi $20 / 40$ ve üzerinde olanların oranı çalışmamızda \%57 iken, ortalama EIDGK değeri 0,5 düzeyindeydi. Olgularımızın büyük çoğunluğunun tatmin edici düzeyde görme düzeylerine ulaştıkları tespit edildi ve ortalama görme düzeylerinin literatürdeki görme düzeyleriyle benzer olduğu görüldü.

Wos ve arkadaşları (2004), travmatik kataraktlı olgularının büyük çoğunluğunu erkek bireylerin oluşturduğunu belirlemişlerdir. Tunus'tan ve Hindistan'dan bildirilen yayınlarda travmatik kataraktlı olgularda cinsiyet açısından bir fark

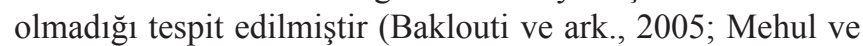
ark., 2011). Çalışmamızdaki bireylerin büyük çoğunluğunu erkekler oluşturmaktadır. Travmatik yaralanmalara maruz kalma açısından toplumumuzda erkekler daha fazla risk altında olduğu için bu farklılığın ortaya çıktığı düşünülebilir.

Travmatik kataraktlı olgularda, primer ve sekonder cerrahinin birbirleri üzerindeki üstünlüğü olgudan olguya değişiklik göstermektedir. Çalışmamızda tüm hastalarımıza sekonder katarakt cerrahisi uyguladığımız için primer cerrahi ile karşılaştırma imkanı bulunmamaktadır. Cerrahi esnasında, ön ve arka kapsül bütünlüğünün güvenli bir cerrahi için gerekli olduğu bilinmektedir. Çoğu travmatik kataraktlı olguda ön ve/veya arka kapsül bütünlügü bozulduğu için cerrahi komplikasyon riski artmaktadır. Özellikle vitre kaybı veya lens partiküllerinin vitreus ile teması sonucu bazı arka segment problemleri ortaya çıkmaktadır. Bu tür problemlerin oluşmaması ve oluştuğu zaman yönetiminin iyi bir şekilde sağlanmas1, görsel prognozu olumlu yönde etkileyeceği için, multidisipliner yaklaşımla ön ve arka segment cerrahları uyumlu bir şekilde çalışmalıdırlar. Özellikle çocuklarda ve şiddetli enflamasyonu olan gözlerde, posterior kapsülotomi ve primer anterior vitrektomi yapılmalıdır. Ayrıca penetran travmaların görsel gelişimi olumsuz yönde etkilediği ve görsel rehabilitasyonun hızlı bir şekilde sağlanması gereken çocuklarda, amliyopi tedavisinin başlanması ve hastaların sıkı bir şekilde takip edilmesi gerekmektedir.

Travmatik katarakt olgularının tedavisinde, en iyi görsel prognozun elde edilmesi için, hastaya ve globun klinik durumuna en uygun cerrahi planlama ve zamanlama yapılmalı, 
oluşabilecek komplikasyonlar öngörülerek tedbirli bir şekilde cerrahi girişim gerçekleştirilmelidir.

Özellikle çocuklarda erken katarakt cerrahisi, görsel rehabilitasyonun bir an önce sağlanması ve ambliopinin önlenmesi için önerilse de postoperatif yoğun enflamasyonun neden olacağı komplikasyonlar, daha sonraki cerrahi sayısını artırabilmektedir. Membranın cerrahi temizlenmesi, disloke olan lensin düzeltilmesi gibi ek işlemler gerekli olabilmektedir. Ayrıca çocuklarda konulan lensin dioptrisi zamanla, hesaplanan ilk dioptriden sapmalar gösterebileceğinden, çoğunlukla kontakt lens kullanımı gündeme gelmektedir. Ancak geç yapılan cerrahilerde de ambliopi riski yanında, özellikle iris altı ve ön kapsül arasında oluşan yapışıklıklar nedeniyle uygun pozisyona lens konulması zorlaşabilmektedir. Ayrıca bekleme sırasında hem yetişkin hem çocuklar için gelişebilecek bir başka olumsuz durum, ön kapsüldeki küçük bir yırtığın, lensin şişmesi ile geriye doğru büyümesi ve güvenli cerrahiyi etkileyecek şekilde geniş yırtıklara dönüşmesidir. Bu nedenle her vaka kendi şartları içinde özel olarak değerlendirilmeli cerrahinin zamanlaması hastaya özelleştirilmelidir.

\section{KAYNAKLAR}

Aldakaf, A., Almogahed, A., Bakir, H., Carstocea, B., 2006. Intraocular foreign bodies associated with traumatic cataract. Oftalmologia. 50, 90-94.

Baklouti, K., Mhiri, N., Mghaieth, F., El Matri, L., 2005. Traumatic cataract: Clinical and therapeutic aspects. Bull. Soc. Belge. Ophtalmol. 298, 13-17.

Brar, G.S., Ram, J., Pandav, S.S., Reddy, G.S., Singh, U., Gupta, A., 2001. Postoperative complications and visual results in uniocular pediatric traumatic cataract. Ophthalmic. Surg. Lasers. 32, 233-238.

Cardillo, J., Stout, J., LaBree, L., Azen, S., Omphroy, L., Cui, J., Kimura, H., Hinton, D., Ryan, S., 1997. Posttraumatic proliferative vitreoretinopathy. The epidemiologic profile, onset, risk factors, and visual outcome. Ophthalmology. 104, 1166-1173.

Dannenberg, A.L., Praver, L.M., Brechner, R.J., Khoo, L., 1992. Penetrating eye injuries in the workplace. The National Eye Trauma System Registry. Arch. Ophthalmol. 110, 843-848.

Ferenc Kuhn, 2010. Traumatic cataract: what, when, how. Graef. Arch. Clin. Exp. Ophthalmol. 248, 1221-1223.

Gradin, D., Yorston, D., 2001. Intraocular lens implantation for traumatic cataract in children in East Africa. J. Cataract. Refract. Surg. 27, 20172025.

Khatry, S.K., Lewis, A.E., Schein, O.D., Thapa, M.D., Pradhan, E.K., Katz, J., 2004. The epidemiology of ocular trauma in rural Nepal. Br. J. Ophthalmol. 88, 456-460.

May, D., Kuhn, F., Morris, R., Witherspoon, D., Danis, R., Matthews, P., Mann, L., 2000. The epidemiology of serious eye injuries from the United States Eye Injury Registry. Graef. Arch. Clin. Exp. Ophthalmol. 238, 153-157.

Mehul, S., Shreya, S., Shashank, S., Prasad, V., Parikh, A., 2011. Visual recovery and predictors of visual prognosis after managing traumatic cataracts in 555 patients. Indian J. Ophthalmol. 59, 217-222.

Pieramici, D.J., Sternberg, P.J., Aaberg, T.M.S., Bridges, W.Z.Jr., Capone, A. Jr., Cardillo, J.A., de Juan, E.Jr., Kuhn, F., Meredith, T.A., Mieler, W.F., Olsen, T.W., Rubsamen, P., Stout, T., 1997. A system for classifying mechanical injuries of the eye (globe). The Ocular Trauma Classification Group. Am. J. Ophthalmol. 123, 820-831.

Rumelt, S., Rehany, U., 2010. The influence of surgery and intraocular lens implantation timing on visual outcome in traumatic cataract. Graef. Arch. Clin. Exp. Ophthalmol. 248, 1293-1297.

Slusher, M.M., Greven, C.M., Yu, D.D., 1992. Posterior chamber intraocular lens implantation combined with lensectomyvitrectomy and intraretinal foreign-body removal. Arch. Ophthalmol. 110, 127-129.

Sternberg, P.J., De Juan, E.J., Michels, R.G., Auer, C., 1984. Multivariate analysis of prognostic factors in penetrating ocular injuries. Am. J. Ophthalmol. 98, 467-472.

Synder, A., Kobielska, D., Omulecki, W., 1999. Intraocular lens implantation in traumatic cataract. Klin Oczna. 101, 343-346.

Wos, M., Mirkiewicz-Sieradzka, B., 2004. Traumatic cataract--treatment results. Klin. Oczna. 106, 31-34. 